\title{
Influence of Knowledge Transfer and Knowledge Conversion on Performance of Commercial Banks in Kenya
}

\author{
Godfrey M. Kinyua, Stephen M. A. Muathe, James M. Kilika
}

School of Business, Kenyatta University, Nairobi, Kenya

Email address:

jefkinyua@gmail.com (G. M. Kinyua),muathe.stephen@ku.ac.ke (S. M. A. Muathe), muathesm@yahoo.com (S. M. A. Muathe), Kilikam3@yahoo.com (J. M. Kilika)

\section{To cite this article:}

Godfrey M. Kinyua, Stephen M. A. Muathe, James M. Kilika. Influence of Knowledge Transfer and Knowledge Conversion on Performance of Commercial Banks in Kenya. Science Journal of Business and Management. Vol. 3, No. 6, 2015, pp. 228-234.

doi: $10.11648 /$ j.sjbm.20150306.13

\begin{abstract}
This study examines the influence of knowledge transfer and knowledge conversion on performance of Commercial Banks in Kenya. The study adopted explanatory and cross-sectional survey design. The target population of this study comprised of all the 43 Commercial Banks in Kenya. The unit of observation was the functional area in each bank. Primary data was collected using a semi-structured questionnaire. The questionnaire was hand delivered and collected later by the researcher in order to enhance the response rate. Secondary data was collected using document review and was used to validate information collected from the questionnaire. The response rate in this study was approximately seventy three percent which was considered adequate for making inferences and drawing conclusions. Quantitative data was analyzed using descriptive and inferential statistics. Descriptive statistics included percentages, frequencies, means, and standard deviations while inferential statistics involved regression analysis. Results from quantitative data analysis were presented using figures and tables. The findings of the study established that knowledge conversion and knowledge transfer have positive influence on performance.
\end{abstract}

Keywords: Knowledge Management, Knowledge Transfer, Knowledge Conversion, Organizational Performance

\section{Introduction}

Understanding the determinants of firm performance has long been a key goal within organizational research [33] because performance is considered the most important criterion in evaluating organizations, their actions, and environments. In this case, a vast body of strategic management literature has sought to offer plausible explanation on performance heterogeneity in organizations [14]. The resource-based view (RBV) considers firm-specific factors as a source of competitive advantage for organizations [13]. It assumes intangible assets such as knowledge, innovation, and intellectual properties have been identified as value drivers and sources of company's competitive advantage.

Competitive advantage in the $21^{\text {st }}$ century has been linked to knowledge-based resources which provide heterogeneous capabilities thus giving each organization its unique character [21]. Extant researchers such as [1] and [11] have focused on knowledge transfer and knowledge conversion as some of the key dimensions of knowledge management with potential to improve firm performance. Knowledge transfer includes a variety of interactions between individuals and groups; within, between, and across groups; and from groups to the organization [26]. Explicit knowledge is formal and systematic [25]. In this case, explicit knowledge is easily communicated and shared creating a common cognitive ground among employees which facilitates the transfer of tacit knowledge. It has been noted that any knowledge transferred between individuals does not only benefits the organization but also tends to improve competence in both the individuals that are involved in the process [34].

It has been noted that individual and organizations create and enlarge knowledge through conversion of tacit knowledge into explicit knowledge and vice versa [36]. Therefore, through knowledge conversion, the whole organization can share explicit knowledge created and convert it to tacit knowledge for individuals Knowledge conversion is considered a critical dimension of KM comprising of the social process through which individuals with different information interact and thereby create new knowledge as well as increase the quality of both tacit and explicit knowledge [29]. 
Commercial Banks plays a critical role in economic development of a nation and are commonly recognized for their contribution to the economic activity, employment, innovation and wealth creation of a country [4]. Moreover, it has been observed that banking is a typical knowledgeintensive industry that involves activities of knowledge exchange rather than exchange of goods [32]. Therefore, managing knowledge has become as important to Commercial Banks as it is for other knowledge based organizations. As noted by [27], KM is indispensable in the banking industry because competition and most of the work in the industry are knowledge-based. Moreover, the last open frontier for banks to create competitive advantage may reside in their ability to leverage knowledge, since banking is not just a business of handling money but also a business that is driven and sustained by information.

Although there are numerous benefits attributed to exploitation of knowledge resources within organizations, the influence of knowledge conversion and knowledge transfer on performance have not sufficiently investigated. In addition, the few studies that have been conducted have focused on developed economies and hardly involved the banking industry [34] and [36]. Therefore, there was a need to investigate the influence of knowledge conversion and knowledge transfer on performance of Commercial Banks in Kenya.

\section{Literature Review}

\subsection{Resource-Based View of the Firm}

The resource-based view (RBV) perceives a firm as an aggregation of resources which are translated by management into strengths and weaknesses of the firm. RBV holds that companies gain sustainable competitive advantages by deploying valuable resources and capabilities that are inelastic in supply [13]. This perspective assumes that organizations must be successful in obtaining and managing valued resources in order to be effective. RBV considers organizational effectiveness as the ability of the organization in either absolute or relative terms, to obtain scarce and valued resources and successfully integrate and manage such resources [7].

Resources are financial, physical, social or human, technological, and organizational factors that allow a company to create value for its customers. Company resources are either tangible or intangible [16]. Intangible resources are the creation of managers and other employees such as the brand names, firm's reputation, knowledge gained through experience, and intellectual property. Tangible resources are physical and include land, buildings, plant, equipment, inventory, and money. Although physical resources may be the origin of above average returns, intangible resources developed through a unique historical sequence and having a socially complex dimension, are responsible for creating and sustaining competitive advantage [22].

RBV assumes resource heterogeneity between competing firms, and further contends that these resources are not mobile, which makes long term, sustainable competitive advantage possible based on internal configuration of strategically relevant resources [13]. In case a resource is firm-specific and difficult to imitate a resource, then a company is likely to have a distinctive competence. Furthermore, a distinctive competence is a unique firmspecific strength that enables a company to better differentiate its products and/or achieve substantially lower costs than its rivals and thus gain a competitive advantage. In the absence of such valuable resources the firm attains only competitive parity. It has been suggested that these valuable resources are frequently found in the organization in the form of tacit knowledge. Therefore, in this study, the postulates of $\mathrm{RBV}$ were used to inform the independent variables [22].

\subsection{Empirical Literature Review}

\subsubsection{Knowledge Transfer}

It has been observed that very few empirical studies have been done on KM and knowledge transfer, and even less in the developing countries [34]. Extant researchers have identified trust, vocabularies, frames of reference, meeting times and venues, broad ideas of productive work, status and rewards that do not go to knowledge owners, absorptive capacity, the belief that knowledge is not the privilege of particular groups, and tolerance as significant cultural factors in the knowledge transfer and sharing process [6] and [36]. The empirical study conducted by [34] confirmed that there is no significant relationship between organizational structure and knowledge transfer performance. However, it was noted that management should consider ensuring that information or knowledge is accessible and shared in the organization.

In addition, [28] revealed that community involvement programs and training contributed to the implementation of $\mathrm{KM}$ practices as employees could freely exchange their ideas and contribute to knowledge sharing, transfer and reuse. Moreover, cross-exposure to different departments was another item that contributed to KM implementation. In this research, the focus was on KM practices including knowledge capturing, knowledge sharing, knowledge transfer, knowledge storing and knowledge reuse. Furthermore, organizational culture was found to be critical in transmitting tacit knowledge among organizational members and transforming tacit knowledge into explicit knowledge in software SMEs. Creation and transfer of knowledge is a critical factor in an organization's success and competitiveness [34].

Moreover, [2] used exploratory research design to examine knowledge transfer process in education and suggested that linkage agents are central actors in the knowledge transfer process. The intervention of linkage agents is critical in helping adapt the knowledge produced by researchers and make it easier to adopt and use by practitioners. Moreover, the effectiveness of this process hinges on major factors including determinants related to knowledge attributes, actors involved in the process and transfer mechanisms. The exploratory research design used in this study does not support statistical analysis and making generalization from the findings. 
$\mathrm{H}_{02}$ : Knowledge transfer has no influence on performance of Commercial Banks in Kenya.

\subsubsection{Knowledge Conversion}

Knowledge conversion is a social process where individuals with different knowledge interact and thereby create new knowledge which grows the quality and quantity of both tacit and explicit knowledge [29]. The purpose of enterprises implementing $\mathrm{KM}$ is to improve and enhance corporate performance [12]. A process model of knowledge creation presupposes that individual and organizations create and enlarge knowledge through conversion of tacit knowledge into explicit knowledge and vice versa. Through knowledge conversion, the whole organization can share the explicit knowledge created and convert it into tacit knowledge for individuals [36].

There are four stages of knowledge conversion commonly known as SECI, involving socialization, externalization, combination, internalization [25]. Knowledge conversion process is a spiral that involves transformation from tacit into explicit knowledge and the subsequent re-transformation from explicit into tacit knowledge [35]. The model showed that tacit knowledge is explicated or codified based on the end result of the knowledge conversion spiral, which is derived from the interactions between explicit and tacit knowledge.

[36] utilized knowledge externalization, knowledge combination, knowledge internalization and knowledge socialization to measure knowledge conversion and revealed that knowledge socialization has no effect on corporate performance. However, in its composite nature, knowledge conversion positively influences corporate performance. This study adopted multiple regression analysis for model specification. Nevertheless, the findings of this study were based on a low response rate of 20.15 percent with only 135 out 650 filling-in and returning the questionnaire which is not adequate for making generalization and drawing conclusions as recommended by [24].

$\mathrm{H}_{01}$ : Knowledge conversion has no influence on performance of Commercial Banks in Kenya.

\subsubsection{Organization Performance}

Understanding the determinants of firm performance has long been a key goal within organizational research [33] because performance is considered the most important criterion in evaluating organizations, their actions, and environments [17]. In the last decade, the influence of KM on performance has been an enduring research theme in organizational theory [9] and [10]. Moreover, there is substantial empirical evidence that KM significantly affect performance [5]. Extant researchers have identified knowledge conversion, knowledge transfer and knowledge application as key dimensions of KM whose integration can improve firm's performance [1] and [39].

It has been observed that $\mathrm{KM}$ is intended to increase the quality and performance of the organizational and help a company to compete effectively with other companies in the market [37]. In addition, the ability to generate new knowledge is a fundamental mechanism of KM systems that influence the performance of a company. [41] noted that effective operation of $\mathrm{KM}$ enables companies to perform more efficiently and survive in the business competitive environment through sustaining their competitive advantages and developing their knowledge assets. RBV and KBV consider knowledge and $\mathrm{KM}$ as critical resources which substantially influence organizational success [3].

According to [15], non-financial indicators are suitable for measuring performance because they can be implemented at all levels of organizations and represent a more precise picture than financial indices whose results are superficial. Furthermore, [42] observed that financial indicators can only reflect the performance of banks in the past and does not reflect the bank's current and future operating conditions. Financial measures of performance which are based on traditional accounting practices and emphasizes short-term indicators such as profit, turnover, cash flow and share prices, are not fully suitable for measuring corporate performance [20]. Therefore, this study adopted non-financial indicators of performance comprising of new products, speed of response to market crises, product improvement, customer retention, and new processes.

\section{Research Methodology}

This study adopted explanatory and cross-sectional survey design as recommended by [31]. As noted by [30] explanatory study helps to establishes causal relationships between the study variables. In addition, a cross-sectional study helps to measure the relationship of variables at a specified time so as to describe the incidence of a phenomenon and how the variables are related. The research design adopted would help to establish the influence of knowledge Transfer and knowledge conversion on performance of Commercial Banks in Kenya.

The dependent variable was considered as a continuous variable and thus regression analysis was adopted as recommended by [8]. Univariate analysis was used to perform regression on the relationships between the two research variables. In particular, knowledge transfer and knowledge conversion were regressed on performance as shown below.

\section{Commercial Bank Performance $=\beta_{1}+\beta_{1}$ Knowledge Transfer $+\mathrm{B}_{2}$ Knowledge Conversion $+\varepsilon$}

The population of this study comprised of all the 43 Commercial Banks in Kenya categorized into large, medium, and small banks on the basis of market share. Five areas were identified in each bank comprising human resource, finance, marketing, information communication technology, and operations in each bank. Thus, a census survey was used where the unit of observation was the functional area in each bank. Proportionate stratified sampling of respondents was undertaken on the basis the five functional areas. In this case, the resulting sample size of 215 was considered representative.

Primary and secondary data were utilized in this study. Primary data was collected using a semi-structured questionnaire administered to managers of the five functional 
areas identified in each bank. Closed-ended questions constructed on a 5-point Likert scale (1-strongly disagree and 5 -strongly agree) provided structured responses that facilitated quantitative analysis, testing of hypothesis, and drawing of conclusion. However, open-ended questions provided additional information that may not have been captured by the closed-ended questions. Secondary data was obtained through document review of published sources including periodicals from CBK such as CBK Bank Supervision Annual Report and CBK Monthly Economic Review.

The pilot study involved fifteen respondents randomly selected from the target population. Face and content validity of the questionnaire items for the two research variables were verified through literature review and expert suggestions as recommended by [24]. Furthermore, factor analysis confirmed that the study variables had construct validity as recommended by [18]. Cronbach's Alpha for the study variables was established at $0.700,0.886$ and 0.712 for knowledge transfer, knowledge conversion and performance respectively which lie within the threshold of at least 0.7 recommended by [23] and thus confirmed the reliability of the items utilized in the research instrument.

A research permit was sought from the National Council of Science, Technology and Innovation (NACOSTI) before embarking on data collection. At the bank level, permission was sought from the bank management to collect data from their managers. The questionnaire was hand delivered and collected later by the researcher in order to enhance the response rate.

\section{Results and Discussion}

The researcher administered 215 questionnaires, out of which 156 were filled-in and returned translating to a response rate of $73 \%$ respondents. This response rate is considered sufficient for making inferences and drawing conclusions from the research data as recommended by [24].

Table 1. Descriptive Statistics for the Study Variables.

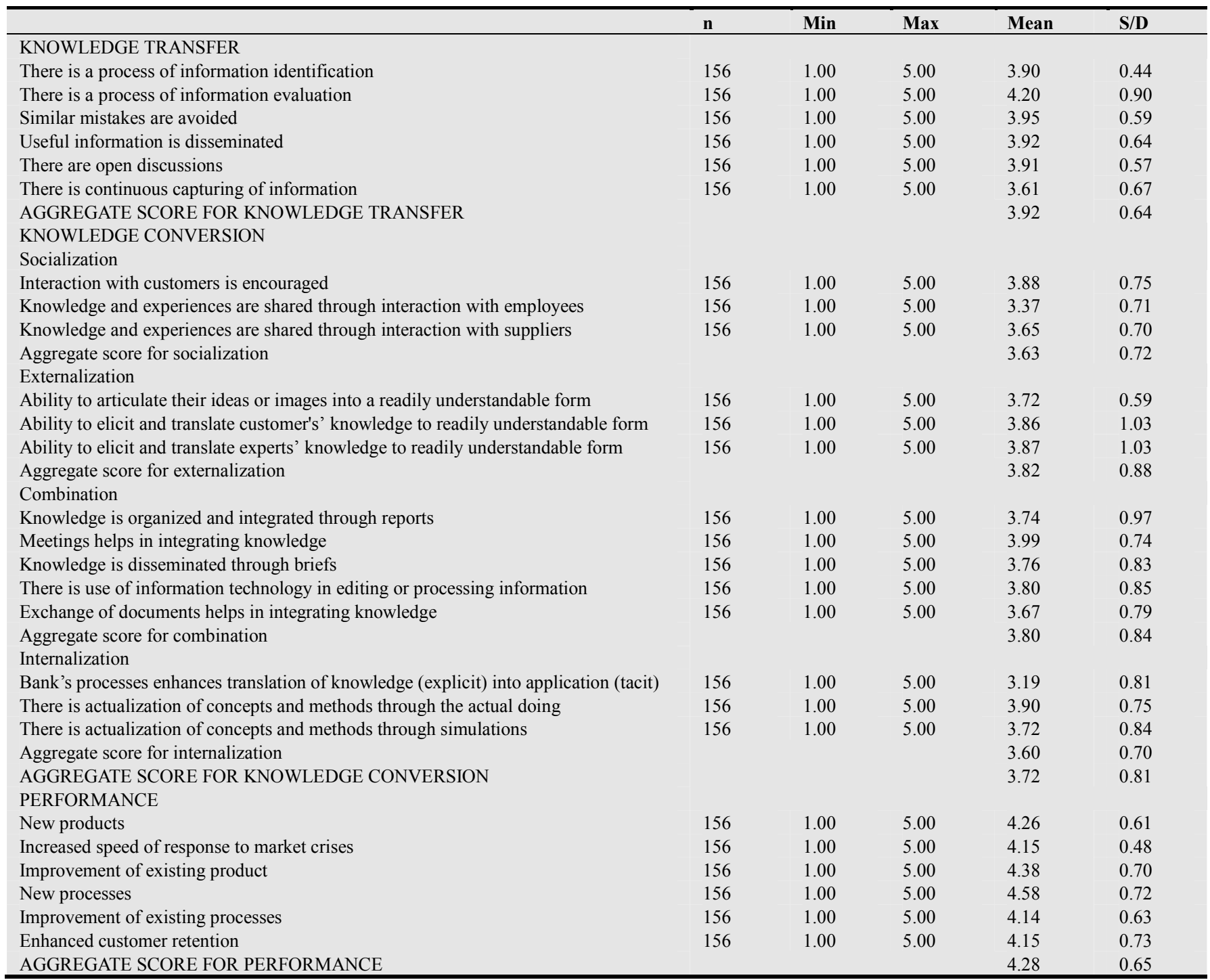

Source: Field Data (2015) 


\subsection{Descriptive Statistics}

The sample measures that were most pertinent to the objectives of this study were sample mean and sample standard deviation were used as a basis for summarizing and describing sample data-set as recommended by [31].

Table 1 shows the aggregate mean score and standard deviation for items on knowledge transfer are 3.92 and 0.64 respectively. This overall mean score approximates to 4.00 (agree) on the 5-point Likert scale and therefore reveals that there is agreement amongst respondents that activities involving transfer of knowledge are practiced in Commercial Banks. Generally, the responses are clustered around mean response as illustrated by the low aggregate standard deviation of 0.64 . Moreover, the low variability of responses implies that the aggregate mean score is a stable and reliable estimator. In this case, the respondents agree that knowledge transfer plays a key role in performance.

The aggregate mean score for the four dimensions of knowledge conversion is 3.72 and thus tends to 4.00 (agree) on the 5-point Likert scale utilized in this study. In addition, the variability of responses from the aggregate mean score is low as indicated by the aggregate standard deviation of 0.81 . This aggregate mean score reveals that the level of activities relating to conversion of knowledge in Commercial Banks is high. In addition, the low aggregate standard deviation implies that the responses are concentrated around the aggregate mean and thus it's a stable and reliable estimator of the true mean. In this case, the narrow variation from the overall mean response confirms that the respondents agreed that knowledge conversion plays a major role in performance.

Furthermore, the overall mean score and standard deviation for items on performance are 4.28 and 0.65 respectively. The aggregate mean score approximates to 4.00 (agree) on the 5-point Likert scale used in this research confirming that there is agreement amongst respondents that the indicators for performance are present in Commercial Banks. The low aggregate standard deviation reveals a narrow variability of responses and thus the aggregate mean responses is a stable and reliable estimator of the population mean. The overall narrow variability of responses from the aggregate mean response confirms that performance is important in Commercial Banks.

\subsection{Test of Hypothesis}

Univariate analysis was used to empirically test the hypothesis adopted for this study at $95 \%$ level of confidence as a statistical basis for drawing conclusions. The responses for each research variable were combined to generate composite scores which were used in the regression analysis. Knowledge transfer and knowledge conversion were regressed on performance as shown in Table 2.

Table 2. Regression Results for the Direct Relationship.

\begin{tabular}{llllll}
\hline & Unstandardized Coefficients & Standardized Coefficients & t & Sig. \\
\hline & & Beta & Std. Error & Beta & \\
(Constant) & 1.803 & .260 & .074 & 1.127 \\
Knowledge Transfer & & .071 & .054 & .316 & .115 \\
Knowledge Conversion & & .049 & .326 & 5.109 \\
R & R Square & .251 & Std. Error of the Estimate & Durbin-Watson \\
$.766 \mathrm{a}$ & .587 & Adj R Square & .27009 & 2.257 \\
& Sum of Squares & .579 & Mean Square & F & Sig. \\
Regression & 15.774 & Df & 5.258 & 72.081 & $.000 \mathrm{~b}$ \\
Residual & 11.088 & 152 & .073 & & \\
Total & 26.862 & 155 & & & \\
a. Predictors: (Constant), Knowledge Transfer, Knowledge Conversion & & & \\
b. Dependent Variable: Performance & & & \\
\hline
\end{tabular}

Source: Field Data (2015)

The regression model estimated in Table 2 for the direct relationship is presented below.

$$
\begin{gathered}
\text { Commercial Bank Performance }=1.803+0.071 \text { Knowledge } \\
\text { Transfer }+0.251 \text { Knowledge Conversion }
\end{gathered}
$$

\subsubsection{Test of Hypothesis One}

The first specific objective sought to establish the relationship between knowledge transfer and performance. The research null hypothesis formulated proposed that knowledge transfer has no relationship with performance. The results of regression analysis in Table 4.14 revealed that knowledge transfer is statistically significant at $\beta=0.071 ; \mathrm{t}=$
$2.316 ; \mathrm{p}=0.019$, thus at $95 \%$ confidence level, knowledge transfer has a positive effect on performance. In addition, an increase of 0.071 in performance is attributed to a unit increase in knowledge transfer. This study concludes that there is a relationship between knowledge transfer and performance of Commercial Banks in Kenya.

\subsubsection{Test of Hypothesis Two}

The second specific objective sought to determine the relationship between knowledge conversion and performance. The corresponding research null hypothesis proposed that knowledge conversion has no relationship with performance. The regression model estimated in Table 2 
revealed that knowledge conversion is statistically significant at $\beta=0.251 ; \mathrm{t}=5.109 ; \mathrm{p}=0.001$, therefore at $95 \%$ confidence level, knowledge conversion has a positive effect on performance. These results also illustrates that a unit increase in knowledge conversion is responsible for increasing performance by 0.251 . This study concludes that knowledge conversion influences performance of Commercial Banks.

\section{Conclusion and Recommendations}

Corporate performance is a key focus of management within organizations. This study investigated the influence of knowledge transfer and knowledge conversion on performance of Commercial Banks in Kenya. On the basis of the findings, the researcher inferred some important conclusions. In regard to the first objective, knowledge transfer is statistically significant and hence knowledge transfer has a positive influence on performance. Similarly, based on the second objective, knowledge conversion is statistically significant and therefore knowledge conversion has a positive influence on performance

Management of Commercials Banks should ensure that information is more available and accessible as well as enhance its flow in order to facilitate transmission of tacit knowledge. Furthermore, management of Commercial Banks should encourage interaction with customers. There is also a need to use bank's processes to enhance understanding and translation of knowledge (explicit) into application (tacit knowledge)

This study sought to investigate the influence of knowledge transfer and knowledge conversion on performance of Commercial Banks in Kenya. In this case, the findings and conclusions are limited to Commercial Banks in Kenya. Future research should focus on validating the findings and conclusion of this study by undertaking replicative researches in other organizations and sectors in Kenya. Moreover, further research should be carried out to investigate the relationship between other dimensions of knowledge management and performance.

\section{References}

[1] Abdul, R. H, Yahya, I. A., Beravi, M. A., \& Wah, L. W. (2008). Conceptual Delay Mitigation Model using a Project Learning Approach in Practice. Construction Management and Economic, Vol. 26, Pp. 15-27.

[2] Becheikh, N., Ziam, S., Idrissi, O., Castonguay, Y. \& Landry, R. (2012). How to Improve Knowledge Transfer Strategies and Practices in Education? Answers from a Systematic Literature Review. Research in Higher Education Journal, Vol. 1, No.1, Pp. 1-21.

[3] Beesley, L. G. \& C. Cooper, C. (2008). Defining Knowledge Management Activities: Towards Consensus. Journal of Knowledge Management, Vol. 12, No.3, Pp. 48-62.

[4] Central Bank of Kenya (2013). Bank Supervision Annual Report 2013. Central Bank of Kenya, Nairobi.

[5] Choi, B. and Lee, H. (2002). Knowledge Management Strategy and its Link to Knowledge Creation Process. Journal of Knowledge Management Practice, Vol. 23 No. 3, Pp. 173-87.

[6] Davenport, T. \& Prusak, L. (1998). Working Knowledge: How Organizations Manage What they Know. Harvard Business School Press. Boston: MA.

[7] Dess, G. G., Lumkin, G. T., Eisner, A. B. \& McNamara, G. (2012). Strategic Management: Text and Cases. McGraw-Hill: New York.

[8] Field, A. (2009). Discovering Statistics using SPSS (2 ${ }^{\text {nd }}$ ed.). Sage: London, UK.

[9] Feng, K., Chen, E. T. \& Liou, W. (2005). Implementation of Knowledge Management Systems and Firm Performance: An Empirical Investigation. Journal of Computer Information Systems, Vol.45, No.2, Pp. 92-104.

[10] Gan, G. G. G., Ryan, C. \& Gururajan, R. (2006). The Effects of Culture on Knowledge Management Practice: A Qualitative Case Study of MSC Status Companies. Kijian Malaysia, Vol. 24, No.1/2.

[11] Gasik, S. (2011). A Model of Project Knowledge Management. Project Management Journal, Vol. 42, No. 3.

[12] Gottschalk, P. (2007). Predictors of Police Investigation Performance: An Empirical Study of Norwegian police as Value Shop. International Journal of Information Management, Vol. 27, No. 1, Pp. 36-48.

[13] Grunert, K. G. \& Hildebrandt, L. (2004). Success Factors, Competitive Advantage and Competence Development. Journal of Business Research, Vol.57, Pp. 459-461.

[14] Hughes, P. \& Morgan, R.E. (2007). A Resource-Advantage Perspective of Product Market Strategy Performance and Strategic Capital in High Technology Firms. Journal of Business Research, Vol.36, No.4, Pp. 503-517.

[15] Jafari, M., Jalal, R., Akhavan, P. \& Mehdi, N. F. (2010). Strategic Knowledge Management in Aerospace Industries: a Case Study. Aircraft Engineering and Aerospace Technology, Vol. 82, No.1, Pp. 60 - 74.

[16] Jones, G. R. \& Hill, C. L. (2009). Strategic Management: An Integrated Approach. Houghton Mifflin: Boston, USA.

[17] Kaplan, R. S. \& Norton, D. P. (2007). Using the Balanced Scorecard as a Strategic Management System. Harvard Business Review, July-August, Pp.150-161.

[18] Kerlinger, F. N., \& Lee, H. B. (2000). Foundations of Behavioral Research $\left(4^{\text {th }}\right.$ ed.). Harcourt College Publishers: New York, USA.

[19] Lee, H. \& Choi, B. (2003). Knowledge Management Enablers, Processes, and Organizational Performance: An Integrative View and Empirical Examination. Journal of Management Information Systems, Vol.20, No.1, Pp. 179-228.

[20] Lee, K.C., Lee, S. \& Kang, I.W.(2005). KMPI: Measuring Knowledge Management Performance. Information and Management, Vol. 42, No. 3, Pp. 469-82.

[21] Liu, C. \& Wei, K.(2009). Knowledge Management and Performance among Top Emerging Market Companies. Communications of the IBIMA, Vol. 7, Pp. 36-43.

[22] Makhija, M. (2003). Comparing the resource-based and market-based views of the firm: empirical evidence from Czech privatization. Strategic Management Journal, Vol. 24, No. 5, Pp. 433-451. 
[23] Marczyk, G., DeMatteo, D. \& Festinger, D. (2005). Essentials of Research Design and Methodology. John Wiley and Sons, Inc.: New Jersey, USA.

[24] Mugenda, A. \& Mugenda, O. (2003). Readings in Research Methods:Quantititive and Qualititative Approaches. African Centre for Technology Studies Nairobi.

[25] Nonaka, I. (1991).The Knowledge-Creating Company. Harvard Business Review, Vol 69, No. 6, Pp 96-104.

[26] Paulin, D. \& Suneson, K. (2012). Knowledge Transfer, Knowledge Sharing and Knowledge Barriers - Three Blurry Terms in KM. The Electronic Journal of Knowledge Management, Vol. 10, No.1, Pp. 81-91.

[27] Rono, C. (2011). Knowledge Management Practices by Commercial Banks In Kenya. Published Thesis, University of Nairobi.

[28] Saini, R. (2013).Model Development for Key Enablers in the Implementation of Knowledge Management. The IUP Journal of Knowledge Management, Vol. 11, No. 2.

[29] Sa'nchez, M. P. S. \& Palacios, M. A.(2008). KnowledgeBased Manufacturing Enterprises: evidence from a case study. Journal of Manufacturing Technology Management, Vol. 19, No. 4, Pp. 447-68.

[30] Saunders, M., Lewis, P. \& Thornhill, A. (2007). Research Methods for Business Students ( $4^{\text {th }}$ ed.). Prentice Hall: Harlow, UK.

[31] Saunders, M., Lewis, P. \& Thornhill, A. (2009). Research Methods for Business Students (5 ${ }^{\text {th }}$ ed.). Prentice Hall: London.

[32] Shih, K. H., Chang, C. J. \& Lin, B. (2010). Assessing Knowledge Creation and Intellectual Capital in Banking Industry. Journal of Intellectual Capital, Vol. 11, No.1, Pp.74 -89 .

[33] Short, J. C., McKelvie, A., Ketchen, D. J. \& Chandler, G. N.(2009) Firm and Industry Effects on Firm Performance: A Generalization and Extension for New Ventures. Strategic Entrepreneurship Journal, Vol. 3, Pp 47-65.
[34] Syed-Ikhsan, S. \& Rowland, F. (2004). Knowledge Management in Public Organizations: A Study on the Relationship between Organizational Elements and the Performance of Knowledge Transfer. Journal of Knowledge Management, Vol. 8, No2, Pp. 95-111.

[35] Takeuchi, H. \& Nonaka, I. (2004). Knowledge Management. John Wiley: Singapore.

[36] Tseng, S. M. (2010).The Correlation between Organizational Culture and Knowledge Conversion on Corporate Performance. Journal of Knowledge Management, Vol. 14, No. 2, Pp. 269-284.

[37] Wilcox King, A. \& Zeithaml, C. P. (2003). Measuring Organizational Knowledge: A Conceptual and Methodological Framework. Strategic Management Journal, Vol. 24, No.8, Pp. 763-772.

[38] Wong, K. \& E. Aspinwall (2005). An Empirical Study of the Important Factors for Knowledge-Management Adoption in the SME Sector. Journal of Knowledge Management, Vol.9, No.3, Pp. 64-82.

[39] Wu, I. \& Lin, H. (2009). A strategy-based Process for Implementing Knowledge Management: An Integrative View and Empirical Study. Journal of the American Society for Information Science and Technology, Vol.60, No. 4, Pp. 789 802.

[40] Yussoff, W. \& Daudi, S. (2010). Knowledge Management and Firms Performance in SMEs: The role of Social Capital as a Mediating Variable. Asian Academy Management Journal, Vol. 15, Pp. 135-155.

[41] Zaim, H., Tatoglu, E. \& Zaim, S. (2007). Performance of Knowledge Management Practices: a Causal Analysis. Journal of Knowledge Management, Vol. 13, No. 6, Pp. 392409.

[42] Zhang, Y. \& Longyi Li, L. (2009). Study on Balanced Scorecard of Commercial Bank in Performance Management System. Proceedings of the 2009 International Symposium on Web Information Systems and Applications (WISA'09) Nanchang, P. R. China, Pp. 206-209. 